\title{
IDENTIFIKASI SENYAWA METABOLIT SEKUNDER EKSTRAK KULIT PISANG KEPOK (MUSA PARADISIACA L) DENGAN METODE KLT
}

\author{
Hasma $^{1 凶}$ Winda $^{1}$ \\ ${ }^{1}$ Jurusan D3 Farmasi STIKES Nani Hasanuddin Makassar
}

\section{ARTICLE INFO \\ Article history}

Submitted : 2019-11-14

Revised : 2019-12-11

Accepted : 2019-12-21

Keywords:
Kepok banana
Secondary metabolites
TLC
Chemical reagents

\section{Kata Kunci:}

Pisang Kepok

Metabolit sekunder

KLT

Reagen kimia \begin{abstract}
Indonesia is a country that is rich in abundant natural plants by having various types of plants which have medicinal properties and are used by some people as traditional medicines. One use of traditional medicine used by the community is the banana plant. So far the community only uses bananas, limited to the use of their fruit, then the banana peel after consumption is only disposed of as waste that is not used optimally by the community. This study aims to identify the chemical compounds found in the skin of Kepok Banana (Musa paradisiaca L.) taken from the pioneer road in the city of Makassar. This identification is carried out using the Thin Layer Chromatography (TLC) method and chemical reagents. Kepok banana peel extract (Musa paradisiaca L.) is made using maceration method, because the method is not only simple, the equipment used is simple, easy to work on, can also avoid damage to compound components due to heat. The yield of Rendamen obtained was $12.06 \%$. Identification was done using Silica Thin Layer Chromatography GF254 with N-hexane eluent: ethyl acetate (6: 4) eluents obtained 5 stains on $366 \mathrm{~nm}$ UV light, namely alkaloids with orange blotches with Rf value (0.13), saponins with blemishes. purple Rf value (0.92), flavonoids with yellow spots $\mathrm{Rf}$ values $(0.33)$ and tannins with blackish orange patches $\mathrm{Rf}$ values $(0.65)$. Based on testing using chemical reagents obtained positive results saponins, flavonoids, tannins and alkaloids. The conclusion of the study showed that the Kepok banana peel extract taken on the pioneering road of Makassar city contained alkaloids, saponins, flavonoids and tannins.
\end{abstract} \begin{abstract}
Indonesia adalah negara yang kaya akan tanaman alami yang berlimpah dengan memiliki berbagai jenis tanaman yang memiliki khasiat obat dan digunakan oleh sebagian orang sebagai obat tradisional. Salah satu penggunaan obat tradisional yang digunakan oleh masyarakat adalah tanaman pisang. Selama ini masyarakat hanya menggunakan pisang terbatas pada penggunaan buahnya, maka kulit pisang setelah dikonsumsi hanya dibuang sebagai limbah yang tidak dimanfaatkan secara optimal oleh masyarakat. Penelitian ini bertujuan untuk mengidentifikasi senyawa kimia yang ditemukan di kulit Pisang Kepok (Musa paradisiaca L.) yang diambil dari jalan perintis di kota Makassar. Identifikasi ini dilakukan dengan menggunakan metode Kromatografi Lapis Tipis (KLT) dan reagen kimia. Ekstrak kulit pisang kepok (Musa paradisiaca L.) dibuat dengan menggunakan metode maserasi, karena metode ini tidak hanya sederhana, peralatan yang digunakan sederhana, mudah dikerjakan, juga dapat menghindari kerusakan komponen senyawa karena panas. Hasil rendemen yang diperoleh adalah 12,06\%. Identifikasi dilakukan dengan menggunakan Kromatografi Lapis Tipis Silika GF254 dengan eluen N-heksana: etil asetat (6: 4) yang diperoleh 5 noda pada cahaya UV $366 \mathrm{~nm}$, yaitu alkaloid dengan bercak orange dengan nilai $\mathrm{Rf}$ $(0,13)$, saponin dengan noda nilai Rf ungu $(0,92)$, flavonoid dengan bintik-bintik kuning Nilai $\operatorname{Rf}(0,33)$ dan tanin dengan patch oranye kehitaman nilai $\operatorname{Rf}(0,65)$. Berdasarkan pengujian menggunakan reagen kimia diperoleh hasil positif saponin, flavonoid, tanin dan alkaloid. Kesimpulan dari penelitian ini menunjukkan bahwa ekstrak kulit pisang Kepok yang diambil di jalan perintis kota Makassar mengandung alkaloid, saponin, flavonoid dan tanin.
\end{abstract}

\section{Corresponding Author:}

\section{Hasma}

Jurusan D3 Farmasi STIKES Nani Hasanuddin Makassar

Telp. 082194139862

Email: hasmaazzah@gmail.com

\section{PENDAHULUAN}

Indonesia kaya tumbuhan alam yang melimpah dengan memiliki berbagai jenis tumbuhan yang berkhasiat sebagai obat dan dimanfaatkan oleh masyarakat sebagai obat tradisional. Obat tradisional tersebut dikenal 
berabad-abad tahun yang lalu dan telah digunakan secara turun temurun oleh masyarakat Indonesia (Umar, 2016).

Salah satu tanaman yang biasa dijadikan sebagai bahan pembuatan obat-obatan tradisional adalah tanaman pisang. Seluruh bagian dari tanaman pisang dapat dimanfaatkan, mulai dari bonggol, batang, bunga, daun dan buahnya. Adapun kandungan gizi yang terdapat dalam setiap buah pisang matang antara lain kalori, protein, lemak, karbohidrat, serat, kalsium, fosfor, besi, vitamin $\mathrm{A}$, vitamin $\mathrm{B}$, vitamin $\mathrm{C}$ dan air. Beberapa penelitian mengatakan bahwa buah pisang bisa membantu mengatasi beberapa penyakit seperti depresi, anemia, tekanan darah, sembelit, sakit jantung, gangguan saraf, dan mensuplai energi dalam otak (Adhayanti dkk., 2017).

Menurut Deborah (2017), kulit pisang kepok memiliki kandungan flavonoid dan fenol sebagai antioksidan yang lebih tinggi dari bagian pisang lainnya. Menurut Indrawati., dkk (2015), yaitu "Efek Antidiabetes Ekstrak Air Kulit Buah Pisang Ambon (Musa paradisiaca L.) Terhadap Mencit (Mus musculus) Model Hiperglikemia" bahwa ekstrak air kulit buah pisang ambon dapat menurunkan kadar gula darah karena adanya efek sinergis senyawa bioaktif flavonoid, fenolik, saponin dan tanin dalam kulit buah pisang ambon. Penelitian Rina (2015), menyatakan kulit buah pisang kepok mentah terkandung beberapa senyawa aktif yaitu saponin, alkaloid, tannin dan flavonoid, dimana senyawa bioaktif diketahui dapat digunakan sebagai agen hipoglikemik (penurun kadar gula darah), ini dikarenakan senyawa bioaktif memiliki kemampuan sebagai antioksidan. Pisang kepok memiliki kandungan antioksidan yang sangat tinggi dan berfungsi sebagai penangkap radikal bebas yaitu senyawa flavonoid. Flavonoid merupakan senyawa kimia yang dilaporkan oleh banyak peneliti sebagai antioksidan, antikanker, antimikrobial, antiaterosklerotik, sebagai imunomodulator, antidiabetes, dan juga sebagai antiinflamasi (Andre, 2017).

Pemanfaatan buah pisang di masyarakat sejauh ini hanya terbatas pada buahnya saja. Buah pisang dapat dikonsumsi baik secara langsung ataupun melalui proses pengolahan terlebih dahulu untuk menjadi sebuah produk makanan ringan, selanjutnya kulit pisang setelah di komsumsi hanya dibuang sebagai limbah yang tidak dimanfaatkan secara optimal oleh masyarakat (Sugiarti dkk, 2017). Berbagai upaya penelitian telah dilakukan untuk mengungkap potensi dan manfaat di dunia kesehatan dari kulit pisang kepok agar dapat dimanfaatkan oleh masyarakat dengan baik. Ekstrak kulit pisang kepok dapat pula dimanfaatkan sebagai sumber antioksidan pada produksi tahu. Pemanfaatan kulit buah pisang kepok tidak terlepas dari adanya kandungan fitokimia di dalamnya. Cara untuk mengetahui kandungan fitokimia atau bahan aktif pada tumbuhan adalah melalui uji fitokimia atau skrining fitokimia. Uji fitokimia dapat dilakukan secara kualitatif maupun secara kuantitatif (Sonja dkk., 2018).

Penelitian menyebutkan bahwa ekstrak kulit buah pisang kapok mengandung saponin, flavonoid, alkaloid dan tanin (Nur, 2017), penelitian sakinah AR, Astrini (2018), menunjukkan bahwa hasil isolasi dari senyawa kimia dari Fraksi Etil Asetat Kulit Buah Pisang Kepok (Musa paradisiaca var Kepok) positif mengandung alkaloid. Hasil skrining fitokimia Ekstrak air kulit pisang kepok mengandung senyawa flavonoid, tanin dan terpenoid (Supriyanti et al., 2015).

Berdasarkan uraian diatas, dilakukan penelitian dan pengujian dari kulit buah pisang kepok untuk mengetahui komponen senyawa metabolit sekunder yang dapat digunakan sebagai pengobatan.

\section{METODE PENELITIAN Jenis Penelitian}

Penelitian dilakukan secara observasi laboratorium untuk mengetahui komponen senyawa metabolit sekunder pada kulit pisang kepok dengan metode Kromatografi Lapis Tipis (KLT). KLT adalah metode yang digunakan untuk menentukan identitas dan kemurnian untuk uji kuantisasi. Secara umum, tehnik ini digunakan untuk memantau reaksi kimia (Meyers, 2008).

\section{Lokasi dan Waktu Penelitian}

Penelitian ini berlokasi di Laboratorium Biologi Farmasi Sekolah Tinggi Ilmu Kesehatan Nani Hasanuddin Makassar. Penelitian dilaksanakan pada bulan Juni 2019.

\section{Populasi dan Sampel}

Populasi penelitian adalah seluruh kulit buah pisang kepok yang telah matang di jalan Perintis Kemerdekaan IV Kota Makassar. 


\section{Pengumpulan Data}

Penyiapan Sampel

Sampel diambil di kota Makassar kecamatan Tamalanrea di jalan Perintis Kemerdekaan IV. Sampel yang diambil yaitu limbah kulit pisang kepok berwarna kuning.

Sampel kulit buah pisang kepok (Musa paradisiaca L.) sudah diambil kemudian dikumpulkan, dicuci dengan air mengalir hingga bersih setelah itu dirajang dan dikeringkan lalu disortasi kering kemudian diblender hingga menjadi serbuk kasar dan siap untuk diekstraksi.

\section{Ekstraksi Sampel Pelarut Etanol}

Sebanyak 250 gram kulit buah pisang kepok (Musa paradisiaca L.) yang telah dikeringkan kemudian dimaserasi dengan cara dimasukkan ke dalam toples kaca lalu direndam dengan etanol $70 \%$ sampai seluruh sampel terendam. Metode ini dilakukan dalam bejana tertutup dan terlindungi.

Sebanyak 250 gram kulit buah pisang kepok (Musa paradisiaca L.) yang telah dikeringkan kemudian dimaserasi dengan cara dimasukkan ke dalam toples kaca lalu direndam dengan etanol $70 \%$ sampai seluruh sampel terendam. Metode ini dilakukan dalam bejana tertutup dan terlindungi dari cahaya selama 3 hari sambil sekali-kali diaduk setiap 1 x 24 jam. Setelah itu, dilakukan penyarian untuk memisahkan cairan dari ampas. Hasil ekstrak etanol diperoleh dikumpulkan kemudian diuapkan hingga diperoleh ekstrak kental cahaya selama 3 hari sambil sekali-kali diaduk setiap 1 x 24 jam. Setelah itu, dilakukan penyarian untuk memisahkan cairan dari ampas. Hasil ekstrak etanol diperoleh dikumpulkan kemudian diuapkan hingga diperoleh ekstrak kental.

\section{Identifikasi Secara KLT}

Cairan pengelusi yang telah dibuat dengan perbandingan eluen $n$-heksan: etil asetat tertentu dimasukkan dalam chamber. Kertas saring yang telah dipotong memanjang kemudian dimasukkan ke dalam chamber hingga menjulur keluar dan chamber ditutup. Cairan dikatakan jenuh bila mana cairan pengelusi telah mencapai ujung atas dari kertas saring.

Dibuat garis lurus pada lempeng KLT 1 $\mathrm{cm}$ (dari batas bawah) dan $0,5 \mathrm{~cm}$ (dari batas atas), dari masing-masing lempeng. Ekstrak etanol kulit buah pisang kepok ditotolkan pada batas bawah lempeng KLT, penotolan dilakukan dengan menggunakan pipa kapiler secara tegak lurus (900 dari permukaan lempeng). Kemudian Lempeng yang sudah ditotol dengan ekstrak sampel dimasukkan kedalam chamber yang telah dijenuhkan sebelumnya. Posisi lempeng berdiri dengan kemiringan 500 dari dinding chamber. Chamber ditutup dan lempeng KLT dibiarkan terelusi hingga batas atas lempeng.

Setelah elusi selesai lempeng dikeluarkan lalu dibiarkan hingga kering dan noda yang terbentuk diamati dengan menggunakan sinar UV pada panjang gelombang $366 \mathrm{~nm}$. Noda yang nampak kemudian diberi tanda.

Setelah diamati noda pada sinar UV $366 \mathrm{~nm}$ namun bercak tidak terlihat selanjutnya disemprot dengan asam sulfat lalu dianginanginkan hingga kering selanjutnya dipanaskan di atas pemanas listrik menggunakan cawan porselin sebagai alas, digoyang-goyangkan hingga diperoleh warna noda yang stabil.Noda warna yang telah tampak kemudian ditandai dan diukur jarak tempuhnya untuk diketahui nilai $\mathrm{Rf}$.

Setelah noda tampak kemudian dihitung nilai Rfnya dengan menggunakan rumus:

$$
\mathrm{Rf}=\frac{\text { Jarak rambat senyawa dari titik awal penotolan hingga pusat bercak }}{\text { Jarak rambat fase gerak dari titik awal penotolan hingga garis depan }}
$$

\section{HASIL PENELITIAN}

Tabel 1. Hasil Uji Kromatografi Lapis Tipis

\begin{tabular}{lcccc}
\hline \multicolumn{1}{c}{ UV 366 nm } & Sinar Tampak & $\mathbf{H}_{\mathbf{2}} \mathbf{S O}_{\mathbf{4}} \mathbf{1 0 \%}$ & Nilai Rf & Keterangan \\
\hline Ungu & Coklat Muda & Merah Muda & 0,92 & Saponin \\
Fluoresensi jingga & Biru & Biru & 0,81 & Flavanoid \\
Jingga kehitaman & Jingga & Jingga & 0,65 & Tanin \\
Kuning & Kuning kehijauan & Kuning & 0,33 & Flavanoid \\
Jingga & Hijau & Hijau Lumut & 0,13 & Alkaloid \\
\hline
\end{tabular}


Berdasarkan nilai Rf yang masuk alkaloid ada 1 noda dengan nilai $\operatorname{Rf}(0,13)$, saponin terdapat 1 noda dengan nilai $\operatorname{Rf}(0,92)$, flavonoid 2 noda dengan nilai $\operatorname{Rf}(0,33),(0,81)$ dan tanin 1 noda dengan nilai $\operatorname{Rf}(0,65)$. Sedangkan berdasarkan warna bercak di bawah sinar UV $366 \mathrm{~nm}$ yaitu alkaloid dengan warna bercak jingga pada nilai $\operatorname{Rf}(0,13)$, saponin dengan warna bercak noda ungu pada nilai $\mathrm{Rf}$ $(0,92)$, flavonoid dengan warna bercak kuning pada nilai $\mathrm{Rf}(0,33)$ dan warna bercak fluoresensi jingga pada nilai $\mathrm{Rf}(0,81)$, dan tanin dengan warna bercak jingga gelap pada nilai $\operatorname{Rf}(0,65)$.

Tabel 2. Hasil Uji Reaksi Kimia

\begin{tabular}{|c|c|c|c|c|}
\hline No & Identifikasi Senyawa & Indikator & Gambar & Keterangan \\
\hline 1. & Alkaloid & $\begin{array}{l}\text { Pereaksi mayer: } \\
\text { kekeruhan putih/ } \\
\text { kuning } \\
\text { Pereaksi wagner: } \\
\text { kekeruhan ruh coklat. } \\
\text { Pereaksi dragendrof: } \\
\text { kekeruhan jingga }\end{array}$ & & (+) Alkaloid \\
\hline 2. & Saponin & $\begin{array}{l}\text { Larutan } \mathrm{HCl} 2 \mathrm{~N} \text { : } \\
\text { Terbentuk buih / busa } \\
\text { yang stabil }\end{array}$ & & (+) Saponin \\
\hline 3. & Flavanoid & $\begin{array}{l}\text { Serbuk Mg dan } \\
\text { larutan } \mathrm{HCl} \text { : } \\
\text { Warna merah, } \\
\text { kuning/ jingga }\end{array}$ & & (+) Flavanoid \\
\hline 4. & Tanin & $\begin{array}{l}\text { Larutan } \mathrm{FeCl}_{3} \text { : } \\
\text { Warna hitam } \\
\text { kebiruan atau } \\
\text { kehijauan }\end{array}$ & & (+) Tanin \\
\hline
\end{tabular}

\section{PEMBAHASAN}

Sampel kulit pisang kepok (Musa paradisiaca L.) disortasi basah untuk memisahkan kotoran-kotoran atau bahan-bahan asing lainnya dari bahan simplisia. Selanjutnya perajangan simplisia dilakukan untuk mempermudah proses pengeringan. Ekstraksi akan berlangsung dengan baik bila diameter partikel diperkecil, pengecilan ukuran ini akan memperluas bidang kontak antara sampel dengan pelarut sehingga jumlah ekstrak yang diperoleh pun semakin besar. Semakin tipis bahan yang dikeringkan, semakin cepat penguapan air sehingga mempercepat waktu pengeringan. Sebelum ekstraksi bahan harus dikeringkan dahulu untuk mengurangi kadar airnya dan disimpan pada tempat yang kering agar terjaga kelembabannya. Tujuan pengeringan untuk menghasilkan simplisia yang tidak mudah rusak, sehingga penyimpanannya dalam jangka waktu yang lama (Umar, 2016).

Metode ekstraksi yang digunakan adalah metode maserasi karena salah satu jenis ekstraksi padat cair yang paling sederhana, pengerjaannya mudah, peralatan yang digunakan juga sederhana, dan dapat menghindari rusaknya komponen senyawa akibat panas. Proses maserasi sangat menguntungkan dalam ekstraksi senyawa bahan 
alam karena dengan perendaman sampel tumbuhan akan terjadi pemecahan dinding dan membran sel akibat perbedaan tekanan antara didalam dan diluar sel, sehingga metabolit sekunder yang ada dalam sitoplasma akan terlarut dalam pelarut organik dan ekstraksi senyawa akan sempurna (Hanani, 2015). Pelarut yang digunakan adalah etanol $70 \%$ merupakan pelarut yang memenuhi syarat dalam pembuatan ekstrak dan bersifat universal yang dapat melarutkan hampir semua zat, baik yang polar maupun nonpolar (Eriadi, 2015).

Metode perendaman (maserasi) dalam pelarut etanol $70 \%$ diharapkan dapat menarik lebih banyak zat aktif yang terkandung di dalam simplisia. Setelah dimaserasi dilakukan penyaringan untuk menahan serbuk kulit pisang (Musa paradisiaca L.) agar tidak menjadi pengotor dan pengganggu saat dilakukan pengujian. Ekstrak etanol yang diperoleh dari hasil ekstraksi kemudian diuapkan secara manual dengan menggunakan kipas angin atau pun hair dryer hingga ekstrak menjadi kental. Didapatkan ekstrak kental sebanyak 30,14 gram dari jumlah sampel awal sebanyak 250 gram sehingga diperoleh nilai randemen sebanyak $12,06 \%$. Selanjutnya diidentifikasi menggunakan KLT dan reaksi kimia sebagai uji pendahuluan.

Pada identifikasi kromatografi lapis tipis menggunakan lempeng silica gel F254 sebagai fase diamnya. Sedangkan untuk fase geraknya digunakan eluen baik yang bersifat polar, semi polar dan non polar. Hasil kromatografi lapis tipis diamati bercak/noda pada penampak bercak yang paling umum digunakan adalah sinar UV. Dikenal pula penampak bercak yang disemprotkan pada fase diam seperti asam sulfat untuk semua golongan senyawa. Sebelummya hasil kromatografi noda yang diperoleh dilihat di bawah sinar UV 366 nm untuk melihat bercak warna pada plat KLT.

Pada penelitian kromatorafi lapis tipis terlebih dahulu lempeng diaktifkan dalam oven pada suhu $120^{\circ} \mathrm{C}$ selama 30 menit dengan tujuan untuk menghilangkan kandungan air yang terdapat pada plat sehingga daya serap plat menjadi maksimal. Kemudian dilakukan metode pengembangan kromatografi dilakukan dengan cara elusi di dalam chamber yang telah dijenuhkan cairan pengelusinya menggunakan kertas saring.

Penjenuhan chamber ini dimaksudkan untuk memastikan homohenitas dalam bejana serta meminimalkan penguapan pelarut dari lempeng KLT (Rubiyanto, 2017). Ekstrak kulit pisang kepok (Musa paradisiaca L) yang telah diambil sebanyak 1 gram lalu diencerkan menggunakan etanol $70 \%$ supaya mempermudah senyawa tertarik oleh eluen dan kemudian ditotolkan pada lempeng KLT menggunakan pipa kapiler secara tegak lurus dan kemudian dimasukkan dalam chamber yang telah dijenuhkan. Pada proses elusi, pori-pori penjerap akan dilalui oleh cairan pengelusi yang bergerak membawa komponen-komponen kimia dan pemisahan akan terjadi oleh adanya perbedaan kelarutan dari masing-masing komponen kimia terhadap cairan pengelusi. Lempeng dikeluarkan dari chamber setelah mencapai batas atas lempeng yang telah ditentukan kemudian diangin-anginkan. Nodanoda yang diperoleh pada proses elusi selanjutnya diamati di bawah sinar UV $366 \mathrm{~nm}$. Sedangkan penyemprotan dengan menggunakan $\mathrm{H} 2 \mathrm{SO} 410 \%$ dilakukan dengan tujuan agar noda-noda yang tidak tampak pada lampu UV dapat tampak setelah dilakukan penyemprotan. Noda warna yang tampak ditandai dan diukur jarak tempuhnya untuk menentukan nilai $\mathrm{Rf}$.

Pada percobaan identifikasi KLT digunakan beberapa eluen yaitu Etil asetat, nheksan, metanol, aquadest, dan kloroform dengan perbandingan etil asetat: n-heksan (7 : 3) dihasilkan 2 bercak noda, etil asetat : nheksan $(4: 1)$ tidak terdapat noda, n-heksan : etil asetat $(7: 3)$ dihasilkan 4 noda namun bercak warna tidak terlalu tampak, etil asetat: metanol: aquadest $(4: 5: 1)$ tidak dihasilkan titik noda, kloroform: etil asetat $(9: 1)$ dihasilkan bercak noda yang tidak terpisah, nheksan : etil asetat : aquadest $(7: 2: 1)$ dihasilkan 3 bercak noda, n-heksan : etil asetat: aquadest $(6: 3: 1)$ dihasilkan 5 bercak noda namun warna yang diperoleh tidak terlalu tampak, sehingga didapatkan perbandingan yang sesuai yaitu n-heksan : etil asetat $(6: 4)$.

Hasil identifikasi kromatografi pada ekstrak kulit pisang dengan menggunakan eluen N-heksan : etil asetat dengan perbandingan $6: 4$ setelah dilakukan elusi secara SGP, hal ini bertujuan agar peningkatan polaritas sistem eluen menyebabkan semua komponen akan terbawa lebih cepat. Setelah diamati di bawah sinar UV $366 \mathrm{~nm}$ terdapat 5 noda. Warna bercak dengan sinar tampak terdapat 5 noda. 
Percobaan yang menggunakan reaksi kimia dengan beberapa uji warna senyawa alkaloid, saponin, flavonoid dan tanin. Pada uji identifikasi alkaloid ekstrak kulit pisang (Musa paradisiaca $L$.) ditambahkan $1 \mathrm{ml} \mathrm{HCl} 2 \mathrm{~N}$ akan terbentuk garam, sehingga alkaloid akan berpisah dengan komponen-komponen lain dari sel tumbuhan yang ikut terekstrak, kemungkinan kompleks kalium alkaloid yang terbentuk tidak sampai batas jenuh sehingga tidak mampu membentuk endapan dan ditambahkan $9 \mathrm{ml}$ aquades lalu dipanaskan selama 2 menit kemudian dinginkan lalu disaring setelah itu pisahkan menjadi 3 tabung, masing-masing tabung ditambahkan $2-3$ tetes masing-masing pereaksi. Pada pereaksi mayer, wagner dan dragendrof hasil pengujian alkaloid ekstrak kulit pisang kepok positif mengandung alkaloid, dimana terjadi perubahan warna yang signifikan ketika ditambahkan pereaksi tersebut. Tidak terbentuk endapan dikarenakan jumlah sampel yang digunakan terlalu sedikit (Nur, 2017).

Pada uji identifikasi saponin ekstrak kulit pisang kepok (Musa paradisiaca L.) ditambahkan $10 \mathrm{ml}$ air panas lalu didinginkan dan kocok kuat-kuat dan kemudian tambahkan 1 tetes $\mathrm{HCl} 2 \mathrm{~N}$ yang akan memunculkan busa stabil. Berdasarkan hasil pengujian saponin ekstrak kulit pisang kepok positif mengandung saponin hal ini ditandai oleh busa yang stabil selama 30 menit setelah di kocok (Nur, 2017).

Pada uji identifikasi flavonoid ekstrak kulit pisang kepok ditambahkan etanol untuk diencerkan yang berfungsi sebagai pembebas flavonoid dari bentuk garamnya lalu dikocok dan panaskan selama 10 menit selanjutnya ditambahkan 0,2 gram serbuk $\mathrm{Mg}$ dan 3 tetes $\mathrm{HCl}$ pekat kocok dan diamkan. Berdasarkan hasil pengujian flavonoid ekstrak kulit pisang kepok positif mengandung flavonoid ditandai dengan terbentuknya warna jingga (Nur, 2017).

Pada uji identifikasi tanin ekstrak kulit pisang kepok ditambahkan $10 \mathrm{ml}$ air panas lalu didihkan selama 5 menit kemudian disaring dan ditambahkan $3-4$ tetes $\mathrm{FeCl} 31 \%$ pada penambahan ini golongan tanin terhidrolisis akanmenghasilkan warna biru kehitaman dan tanin akan terkondensasi akan menghasilkan warna hijau kehitaman. Perubahan warna ini terjadi ketika penambahan $\mathrm{FeCl} 3$ yang bereaksi dengan salah satu gugus hidroksil yang ada pada senyawa tanin. Berdasarkan hasil pengujian tanin ekstrak kulit pisang kepok positif mengandung tanin (Nur, 2017).

Nilai Rf yang memenuhi syarat KLT yang baik, yaitu dengan rentang nilai Rf $0,2-$ 0,8 pada penelitian Tammy Mulia Dewi yang mencantumkan pada perbandingan penelitiannya yang berjudul "analisis kuantitatif residu antibiotika tetrasiklin pada madu". Pada penelitian yang telah dilakukan menunjukkan bahwa tidak semua nilai Rf kulit pisang kepok (Musa paradisiaca L.) memenuhi syarat KLT yang baik.

Hal ini sejalan dengan penelitian Sri herlina yang berjudul "Uji Fitokimia Kulit Pisang Kepok (Musa paradisiaca L.) Bahan Alam Sebagai Pestisida Nabati Berpotensi Menekan Serangan Serangga Hama Tanaman Umur Pendek". Pada teori pendukungnya yang menyatakan tentang hasil skrining fitokimia dari kulit pisang kepok mengandung senyawa flavonoid, saponin, steroid, alkaloid, tanin.

\section{KESIMPULAN}

Ekstrak etanol kulit buah pisang kepok (Musa paradisiaca L.) diidentifikasi dengan metode Kromatografi Lapis Tipis (KLT) terdapat senyawa alkaloid, saponin, flavonoid dan tanin.

\section{DAFTAR PUSTAKA}

Adhayanti, Ida., Tajuddin A., Rika R. (2018). Uji Kandungan Total Polifenol Dan Flavonoid Ekstrak Etil Asetat Kulit Pisang Raja (Musa Paradisiaca Var. Sapientum). Prodi Farmasi Poltekkes Kemenkes Makassar. Media Farmasi Vol. XIV No. 1.

Andre P., Farras C., Wulan., Rini S., M Yogi., Tri U. (2017). Efektivitas Ekstrak Kulit Pisang Kepok (Musa acuminata) dan Ekstrak Daun Salam (Syzygium polyanthum (wight) Walp) sebagai Agen Preventif terhadap Diabetes Melitus Tipe 2. Bagian Mikrobiologi, Fakultas Kedokteran, Universitas Lampung. J Agromedicine Unila - Vol. 4 No.2

Sakinah AR, Astrini. (2018). Isolasi Senyawa Metabolit Sekunder dari Fraksi Etil Asetat Kulit Buah Pisang Kepok (Musa paradisiaca var Kepok). Undergraduate (S1) thesis, Universitas Islam Negeri Alauddin Makassar.

Deborah N., Gemayangsura. (2017). Khasiat Kulit Pisang Kepok (Musa acuminata) sebagai Agen Preventif Ulkus Gaster. 
Fakultas Kedokteran, Universitas Lampung. Majority - Vol.4 No. 8

Endang, Hanani. (2015). Analisis Fitokimia. Jakarta: EGC.

Eriadi, Aried., Helmi A., Zet R., Barmitoni. (2015). Pengaruh Ekstrak Etanol Daun Binahong (Anredera cordifolia (Tenore) Steen) Terhadap Penyembuhan Luka Sayat Pada Tikus Putih Jantan. Sekolah Tinggi Ilmu Farmasi Padang. Jurnal Farmasi Higea,Vol. 7, No. 2

Indrawati, Sri., Yuliet., Ihwan. (2015). Efek Antidiabetes Ekstrak Air Kulit Buah Pisang Ambon (Musa Paradisiaca L.) Terhadap Mencit (Mus Musculus) Model Hiperglikemia. Jurusan Farmasi Fakultas MIPA. Universitas Tadulako, Palu. Galenika Journal of Pharmacy-Vol. 2 (1) : 133 - 140 ISSN : 2442-8744

Meyers, C. L. F., \& Meyers, D. J. (2008).Thin-layer chromatography. Current protocols in nucleic acid chemistry, A-3D

Nur, Dwi R., David K. (2017). Analisis Fitokimia Ekstrak Kulit Pisang Agung Semeru Dan Mas Kirana. Pendidikan Biologi, FP. MIPA, IKIP PGRI Jember. Jurnal Biologi dan Pembelajaran Biologi Vol. 2 No. 2 Tahun 2017. (p-ISSN 25277111; e-ISSN 2528-1615).

Rina D., Poeranto, Sri YS., Dwi Y. (2015). Uji Efektifitas Antifungal Ekstrak Kulit Pisang Kepok (Musa acuminata $x$ balbisiana) Mentah Terhadap Pertumbuhan Candida albicans Secara In Vitro. Majalah Kesehatan FKUB Vol.
2 No. 3.

Rubiyanto, Dwiarso. (2017). Metode Kromatografi. Yogyakarta: Deepublish.

Sonja V.T. Lumowa., Syahril B. 2018. Uji Fitokimia Kulit Pisang Kepok (Musa Paradisiacal.) Bahan Alam Sebagai Pestisida Nabati Berpotensi Menekan Serangan Serangga Hama Tanaman Umur Pendek. Jurnal Sains dan Kesehatan. Vol 1. No 9. e-ISSN: 24076082

Sugiarti, Nana., Novia A., Eka K. (2017). Identifikasi Dan Analisis Kadar Flavonoid Ekstrak Etanol Kulit Buah Pisang Kepok (Musa Paradisiaca Forma Typica) Mentah Dengan Metode Spektrofotometri Uv-Vis. Akademi Farmasi ISFI Banjarmasin.

Supriyanti, F. M. T., Suanda, H., \& Rosdiana, R. (2015). Pemanfaatan Ekstrak Kulit Pisang Kepok (Musa bluggoe) Sebagai Sumber Antioksidan Pada Produksi Tahu. In Seminar Nasional Kimia dan Pendidikan.

Umar, Halim A., Reny S., Asril B., Fadillah., Astuti A., Marwati., Lisa R. (2016). Determinasi Dan Analisis Finger Print Tanaman Murbei (Morus Alba Lour) Sebagai Bahan Baku Obat Tradisional Dengan Metode Spektroskopi Ft-Ir Dan Kemometrik. Sekolah Tinggi Ilmu Farmasi Makassar. Jurnal Ilmiah Farmasi - UNSRAT Vol. 5 No.1 ISSN 2302 2493. 